\title{
Narrativas de aulas de matemática: reificações de comunidades de prática
}

\author{
Lilian Aragão da Silva \\ Airam da Silva Prado ${ }^{2}$ \\ Jonei Cerqueira Barbosa ${ }^{3}$
}

\begin{abstract}
Resumo: Este artigo tem o propósito de analisar formas de desenvolver aulas de matemática (processo) e formas de escrever (produto) esboçadas em narrativas de aulas. Para isso, utilizar-se-á a perspectiva da aprendizagem situada, a fim de promover uma descrição teórica para ilustrar como as narrativas, produzidas por professores de matemática que fazem parte do Observatório da Educação Matemática (OEM-Bahia), se constituem como produtos/processos da conexão entre as práticas sociais de que esses professores participam. Os resultados desta pesquisa apontam que as narrativas podem ser compreendidas teoricamente como (re)reificações de uma comunidade interconectada com outra comunidade (ou outras comunidades) a partir do objeto de fronteira (a tarefa) e do broker (o professor).
\end{abstract}

Palavras-chave: narrativas, aulas de matemática, reificações

\section{Narratives of mathematics classes: reifying communities of practice}

\begin{abstract}
This article aims to examine ways of developing math classes (process) and how to write (product) in narratives of classes. To do it, we will use the perspective of situated learning in order to promote a theoretical description and illustrate how narratives produced by mathematics teachers taking part in the Mathematics Education Watch (OEM-Bahia) are constituted as products / processes that connect social practices which teachers participate. The findings suggest that the narratives may be theoretically understood as (re)reifications of an interconnected community with another one (or other communities) linked by the boundary object (the task) and the broker (the teacher).
\end{abstract}

Keywords: narratives, mathematics classes, reifications

1 Doutoranda em Ensino, Filosofia e História das Ciências pela Universidade Federal da Bahia. Mestre em Ensino, Filosofia e História das Ciências pela Universidade Federal da Bahia em 2013. Professora do Curso de Licenciatura em Matemática da Universidade Federal do Recôncavo da Bahia, em Amargosa-Ba. Email: lilianufrb@gmail.com

2 Doutoranda em Ensino, Filosofia e História das Ciências pela Universidade Federal da Bahia. Mestre em Ensino, Filosofia e História das Ciências pela Universidade Federal da Bahia em 2014. Email: airamprado@ gmail.com

3 Doutor em Educação Matemática pela Universidade Estadual Paulista Júlio de Mesquita Filho em 2001. Docente do Departamento II da Faculdade de Educação, Universidade Federal da Bahia (UFBA). Docente Permanente do Programa de Pós-Graduação em Educação e do Programa de Pós-Graduação em Ensino, Filosofia e História das Ciências, ambos da UFBA. Email: jonei.cerqueira@ufba.br 


\section{Introdução}

Dentre as modalidades de desenvolvimento profissional de professores, têm se destacado as reuniões de professores em grupos que buscam o empreendimento de uma prática que permita o engajamento dos membros com vistas a alcançar objetivos comuns. Esses grupos, que podem ser vistos como comunidades de prática (Wenger, 1998), têm sido foco de estudos que abordam a formação continuada de professores (Beline, 2012; Cyrino, 2013; Fiorentini, 2009; Nagy, 2013).

O conceito de comunidades de prática (CoP), segundo Lave e Wenger (1991), combina dois conceitos teóricos importantes, a saber: comunidade e prática. A comunidade é compreendida como um conjunto de configurações sociais que se caracterizam pelas seguintes características:

- o empreendimento conjunto: refere-se às metas, aos objetivos e às responsabilidades de fazer algo de maneira coletiva, a fim de manter unido aquele grupo de pessoas;

- o compromisso mútuo: vincula-se ao compromisso de fazer parte ou pertencer às relações entre os participantes, bem como à participação nas ações e na negociação desenvolvidas por um grupo de pessoas;

- o repertório compartilhado: diz respeito aos recursos criados para produzir ou negociar significados que estejam de acordo com o empreendimento conjunto daquele grupo de pessoas, tais como rotinas, palavras, gestos, maneiras de fazer, relatos, símbolos, instrumentos, ações, conceitos, etc.

O conceito de prática denota fazer algo em um contexto histórico e social que concede um significado àquilo que fazemos, seja de modo explícito ou implícito. Por conta disso, Wenger (2001) aponta que a prática é sempre uma prática social. Assim, a combinação desses dois termos forma uma unidade conceitual que faz referência a comunidades sociais que desenvolvem uma prática social, a partir do momento em que um grupo de pessoas, por meio de uma interação conjunta, comunga um sistema de atividades no qual todos compartilham ou produzem significados sobre aquilo que fazem e até o que não fazem. Mais do que se reunir em grupo, as CoP se caracterizam pelo sentimento de "pertencimento" e pela participação de seus membros.

Nas palavras de Wenger (2001):

Todos nós pertencemos a comunidades de prática. Em casa, no trabalho, na escola, em nossos passatempos: pertencemos a várias comunidades de prática em qualquer momento dado. E as comunidades de prática às quais pertencemos mudam no curso de nossa vida. Na verdade, as comunidades de prática estão por toda parte. (p.23) 
Com isso, o autor sustenta que esse conceito se amplia para várias configurações que se ajustam nas três características de uma comunidade, ao possuir uma prática social. Mesmo naquelas em que há uma informalidade, ou melhor, em que não estão explícitos os repertórios, o empreendimento e o compromisso, esse conceito se satisfaz, como é, por exemplo, o caso da família. Particularmente na escola, esse conceito pode ser aplicado. Segundo Wenger (2001), ali "surgem comunidades por toda parte: na aula ou no pátio do recreio, de uma maneira oficial ou espontânea” (p.24). Apesar de o currículo ser isolado por disciplinas e de haver relações antagônicas entre os participantes de forma complementar ou relações de autoridade, de aliança ou de oposição, de harmonia ou de conflito, etc., há CoP ${ }^{4}$. Desse modo, o autor conclui que existem vários tipos de comunidades de prática.

No âmbito da literatura em Educação Matemática, no Brasil, os recentes estudos colocam lentes sobre os modos como professores de matemática participam das CoP e organizam e desenvolvem seus empreendimentos (Rocha \& Cyrino, 20125); sobre a forma como essa participação conduz as diferentes trajetórias de aprendizagens (Nagy, 20136) e como são constituídas identidades de professores de matemática no interior das CoP (Beline, 20127 ).

Esses estudos têm focalizado grupos de professores que se reúnem para desenvolver uma prática social. Além desses, há outros grupos mencionados na literatura que se configuram como CoP, tais como o Grupo de Pesquisa e Produção em Educação Matemática (GPPEM) ${ }^{8}$ e o Grupo de Sábado (GdS $)^{9}$. Há uma recorrência das investigações com o uso dessa teoria, para analisar apenas CoP cujos sujeitos participam de grupos colaborativos. Entretanto, ser CoP também inclui relações conflituosas, bem como imposições externas e internas.

Entre os empreendimentos conduzidos por grupos de professores de matemática nas comunidades citadas, uma atividade comum a elas refere-se à construção de tarefas e narrativas de aulas. Por exemplo, no Brasil, há um número considerável de pesquisas que veem a produção escrita como ferramenta valiosa na formação docente, por meio da publicação de textos, relatos e reflexões dos professores que atuam em sala de aula (Fiorentini, 2009; Passos \& Galvão, 2011). Essas narrativas

4 Dessa maneira, essa perspectiva pode ser utilizada como lente teórica para analisar a CoP-Sala de aula, uma vez que, mesmo embasada num modelo tradicional, há empreendimentos conjuntos, repertórios compartilhados, compromissos mútuos e prática social que estão além de aprender determinadas disciplinas, mas que levam seus participantes a constituir-se como estudantes ao longo de cada ano letivo e determinam as relações estabelecidas entre eles.

5 O estudo investiga a Comunidade de Professores que Aprendem e Ensinam Matemática (CoP-PAEM).

6 O estudo investiga a Comunidade de Professores de Matemática dos Anos Iniciais (CoP-MatAnosIniciais).

7 O estudo investiga a Comunidade de Prática de Formação de Professores (CoP-Açãoz).

8 A CoP é apresentada no trabalho de Maciel, Braga e Orlanda (2008).

9 A CoP é apresentada no trabalho de Cristovão e Castro (2013). 
podem ser vistas como modos de investigar indícios da experiência (Nacarato, Passos, \& Silva, 2014).

Marquesin e Passos (2009) argumentam que as narrativas se constituem como objetos que podem criar oportunidades para que o professor examine a prática real de ensino, de forma a ampliar seus saberes e a potencializar a docência, com vistas a planejar, implementar, analisar e revisar aulas que eles mesmos ministram nas escolas. Nesse sentido, a escrita de narrativas pode possibilitar que o sujeito atribua significados aos fatos que vivenciou e reconstrua a compreensão que tem de si mesmo.

A partir das perspectivas apresentadas pelos autores supracitados, consideramos que a narrativa pode ser entendida como produto/objeto que, de certo modo, pode "congelar" maneiras de fazer de um grupo social em relação a uma determinada prática. Ao projetar no mundo um entendimento, uma compreensão acerca dessa prática por meio da escrita de narrativas de aulas, os indivíduos estão envolvidos em um processo que a perspectiva teórica denomina de "reificação" (Wenger, 1998).

A fim de trazer algumas contribuições para esse debate, neste artigo apresentamos uma análise de narrativas de aulas escritas por membros do Observatório da Educação Matemática localizado na Bahia, o qual será identificado aqui pela expressão "OEM-Bahia”10. A prática social dessa comunidade refere-se ao desenvolvimento de materiais curriculares educativos (MCE), cuja finalidade é apoiar a aprendizagem dos estudantes e dos professores, podendo apresentar detalhes da implementação de uma tarefa em sala de aula, como narrativas, registros dos estudantes, comentários, etc. (Schneider \& Krajcik, 2002).

Aqui utilizamos conceitos da perspectiva da aprendizagem situada (Lave \& Wenger, 1991; Wenger, 1998, 2001) a fim de construir uma compreensão teórica para ilustrar como as narrativas produzidas por professores de matemática e por outros membros se constituem como produtos e como processo da conexão entre as práticas sociais das quais os sujeitos participam.

10 O Observatório da Educação Matemática na Bahia (OEM-Bahia) reúne voluntariamente estudantes da graduação e pós-graduação, pesquisadores e professores que ensinam matemática na educação básica em torno de um projeto de pesquisa e desenvolvimento, no âmbito do Programa Observatório da Educação da Coordenação de Aperfeiçoamento de Pessoal de Nível Superior (CAPES) e do Instituto Nacional de Estudos e Pesquisas Educacionais Anísio Teixeira (INEP), com o propósito de desenvolver materiais curriculares educativos sobre tópicos de matemática para os anos finais do ensino fundamental. Para a etapa de desenvolvimento, o grupo se reúne periodicamente, e todos os membros assumem o compromisso de participar das ações e das negociações desenvolvidas no grupo. Nessas reuniões são criados os repertórios para o empreendimento conjunto (a responsabilidade no desenvolvimento da prática social e a manutenção da coesão dos participantes desse grupo). Portanto, entendemos que o grupo constitui uma comunidade de prática, em razão da configuração social e da prática social envolvida. 
A seguir, discutiremos outros conceitos teóricos dessa perspectiva que fundamentaram a análise dos dados deste texto.

\section{Dualidade entre "participação" e "reificação"}

O termo "participação" é um conceito-chave nas perspectivas de Lave e Wenger (1991) e de Wenger (1998, 2001), que designa a experiência social de viver no mundo a partir da afiliação ou do pertencimento a comunidades de prática e da interação ativa em empreendimentos sociais. Dessa forma, de acordo com Wenger (2001), "a participação é tanto pessoal como social” (p. 80), pois envolve a pessoa no mundo e as relações que ali são estabelecidas. Por isso, trata-se de uma teoria social que considera a aprendizagem como fenômeno social decorrente da participação em comunidades de prática.

Além disso, a participação é descrita como um processo complexo que combina falar, fazer, pensar, sentir e pertencer. Não podemos inferir, por exemplo, que um computador participe de uma comunidade de prática, embora possa formar parte dessa prática e desempenhar um papel ativo na execução de certas coisas. Esse conceito é reservado para os sujeitos que são membros e negociam significados partilhados e/ou produzidos em comunidades. Wenger (1998) refere-se ao conceito de negociação de significado como um meio de caracterizar o processo pelo qual nós experimentamos o mundo e nosso engajamento nele, o que envolve tanto interpretação como ação.

Os estudos de J. Pereira (2013), M. Pereira (2013) e Souza (2011) tematizaram a participação dos professores e dos alunos quando desenvolveram tarefas de Geometria na sala de aula. Os autores concluíram que a forma como os alunos participam da aula depende da tarefa, dos materiais utilizados e da intervenção do professor, ou seja, de como eles negociam e compartilham determinados repertórios comuns. Tais estudos não caracterizaram a sala de aula como uma $\mathrm{CoP}$, uma vez que analisaram pontualmente a participação dos alunos no desenvolvimento de uma tarefa em poucas aulas ${ }^{11}$.

Já os estudos de Fiorentini (2009) e Lucena (2014) focalizaram a participação ou o relato das trajetórias de participação dos professores em grupos colaborativos e mostraram, de maneira geral, que a participação em comunidades contribui para mudanças docentes. Tais mudanças podem favorecer a aprendizagem dos estudantes na sala de aula no momento em que os professores reconhecerem seu próprio

11 Embora sejam pontuais a observação e a análise do fenômeno investigado nessas pesquisas, seria possível investigar características dessa comunidade, que as classificam como comunidades de prática, a fim de encontrar mais detalhes que possam ajudar a compreender a participação dos sujeitos. 
diálogo com os estudantes como promissor na construção de significados. Nesse último caso, há uma conexão entre duas CoP.

Por outro lado, essa perspectiva teórica reconhece que, além da participação, há outra dimensão denominada de "reificação"12, um conceito muito útil para descrever nosso compromisso no mundo como produtor de significados. Etimologicamente, esse termo significa "converter algo em coisa". Entretanto, esse termo vai além de uma conversão numa coisa (objeto material e concreto), pois pode proporcionar um atalho à comunicação e à projeção ou ao "congelamento" de nossas experiências no mundo.

Qualquer comunidade de prática produz abstrações, instrumentos, símbolos, relatos, termos e/ou conceitos que "coisificam" algo dessa prática em uma forma padronizada. Assim, esse termo pode fazer referência tanto ao processo (na negociação ou produção de significados) quanto ao produto (objeto material ou concreto). Dessa maneira, a participação e a reificação são, ao mesmo tempo, distintas e complementares, pois formam, simultaneamente, uma unidade e uma dualidade.

Retomando a discussão nos estudos de Lucena (2014), J. Pereira (2013), M. Pereira (2013) e Souza (2011), podemos inferir conceitos teóricos não tematizados em suas pesquisas, mas que explicam que a participação está intimamente relacionada a coisas materiais e concretas, bem como a ideias e significados produzidos em uma CoP. Ou seja, a participação e a reificação formam um processo dual, a fim de dar sentido à negociação de significados e ao repertório compartilhado por essa comunidade.

Já os estudos de Fiorentini (2009) apresentam que a CoP-GdS desenvolve ou produz continuamente determinadas reificações, a saber: conceitos e significados próprios sobre tarefas e atividades de natureza exploratória e/ou investigativa; rotinas próprias; saberes experienciais; maneiras de ser-estar professor nas escolas atuais; postura reflexiva e investigativa sobre a prática docente; relatos, narrativas ou histórias escritas de aulas; discurso próprio envolvendo signos e palavras do ensino da matemática. Tais reificações estão imbricadas no processo de participação dos sujeitos nessa comunidade.

Particularmente os relatos, as narrativas ou as histórias escritas de aula constituem o foco deste trabalho, pois se trata de reificações que reúnem novos significados e que compartilham experiências de professores e estudantes, ao desenvol-

12 No inglês esse termo é escrito reification (Wenger, 1998), enquanto no espanhol se registra coisificación (Wenger, 2001). Por isso, é comum encontrarmos em estudos a tradução desse termo como "reificação" e, em outros, como "coisificação". Neste artigo, utilizaremos o termo "reificação", pois acreditamos que o outro termo remete apenas a coisas, denotando objetos materiais e concretos. 
verem uma tarefa na CoP-Sala de aula. Em paralelo, essas reificações representam uma projeção ou um "congelamento" de experiências e negociação de significados que foram compartilhados no Observatório da Educação Matemática (OEM), o qual possui as características de uma CoP e, por conta disso, o denominaremos de CoP-OEM.

Nesse caso, há duas CoP identificadas. Na CoP-OEM, a tarefa representa uma reificação que dá origem a outra reificação, que é o foco deste trabalho e nomearemos de "narrativas de aulas". Por outro lado, a tarefa pode ser identificada como um objeto de fronteira, que conecta as duas CoP (a sala de aula e o OEM-Bahia).

Já o professor pode ser interpretado como o broker (intermediador), ou seja, como o responsável pela conexão entre as CoP. Nos estudos de Fiorentini (2009), um membro da CoP-GdS reconheceu as escritas de narrativas como um recurso fundamental para relatar aos colegas lições e aprendizagens obtidas com a experiência no grupo e na sala de aula. Isso se deve ao fato de ele ter participado paralelamente dessas duas CoP e conectado reificações e aprendizagens de um no outro e vice-versa.

Na próxima seção, detalharemos os materiais empíricos produzidos pelo CoP-OEM utilizados nesta pesquisa e o percurso metodológico que desencadeou o presente trabalho.

\section{Contexto e método da pesquisa}

As narrativas analisadas neste estudo compõem um MCE elaborado pela CoP-OEM, da qual os autores deste artigo são também membros. Um dos componentes desse material é a tarefa; outro é a narrativa do professor sobre a implementação dela. Como nosso objetivo se centra sobre a análise do texto escrito, ou seja, das narrativas de aulas, o método qualitativo foi o mais indicado (Johnson \& Christensen, 2012).

Para compor os materiais empíricos da pesquisa, contamos com as narrativas de aulas produzidas pelos professores participantes da CoP-OEM e discutidas no próprio grupo. Elas foram, posteriormente, publicadas como parte dos MCE em um ambiente virtual. ${ }^{13}$ Tais materiais constituem os documentos utilizados para a análise dos dados desta pesquisa, conforme previsto em Alves-Mazzotti (2002).

Ao analisar o corpus, procuramos identificar elementos que evidenciassem as reificações decorrentes das negociações da CoP-OEM, assim como indícios das reificações que sinalizam as negociações da CoP-Sala de aula. Foram analisadas seis narrativas - cada uma descreve o desenvolvimento de uma aula em torno de uma tarefa específica, a qual também foi elaborada no âmbito da CoP-OEM. O quadro 1 , a seguir, apresenta as narrativas analisadas e relacionadas com os objetivos das

13 http://www.educacaomatematica.ufba.br. 
tarefas propostas. Devido às limitações de espaço, não foi possível reproduzi-las no corpo do artigo, de modo que remetemos o leitor ao ambiente virtual. ${ }^{14}$

Indicaremos cada narrativa por uma sigla que contém a inicial do nome do professor que desenvolveu a tarefa em sala de aula.

Quadro 1: Objetivos das tarefas e narrativas

\begin{tabular}{|c|c|c|}
\hline Professor (sigla) & Objetivos da tarefa & Título da Narrativa \\
\hline $\begin{array}{l}\text { Professora Cecília } \\
\text { (C) }\end{array}$ & $\begin{array}{l}\text { Reconhecer ângulos internos de um polígono con- } \\
\text { vexo qualquer; calcular a soma das medidas dos } \\
\text { ângulos internos de um polígono convexo qual- } \\
\text { quer; e generalizar a soma das medidas dos ângulos } \\
\text { internos de um polígono de } n \text { lados. }\end{array}$ & $\begin{array}{l}\text { "A soma das medidas dos } \\
\text { ângulos internos de um } \\
\text { polígono qualquer" }\end{array}$ \\
\hline $\begin{array}{l}\text { Professora Giovanna } \\
\qquad(\mathrm{G})\end{array}$ & $\begin{array}{l}\text { Verificar que um triângulo equilátero tem três } \\
\text { ângulos internos congruentes e iguais a sessenta } \\
\text { graus; que o triângulo isósceles possui dois lados } \\
\text { de mesma medida e dois ângulos congruentes; e } \\
\text { que o triângulo escaleno possui três lados de medi- } \\
\text { das diferentes e três ângulos de medidas diferentes. }\end{array}$ & $\begin{array}{l}\text { "Classificando triângulos } \\
\text { em uma turma do Ensino } \\
\text { Fundamental" }\end{array}$ \\
\hline $\begin{array}{l}\text { Professora Mércia } \\
\text { (M) }\end{array}$ & $\begin{array}{l}\text { Reconhecer e representar os ângulos externos de } \\
\text { um triângulo, assim como a soma de suas medidas. }\end{array}$ & $\begin{array}{l}\text { "A implementação de uma } \\
\text { tarefa sobre ângulos exter- } \\
\text { nos de um triângulo com o } \\
\text { software Geogebra" }\end{array}$ \\
\hline Professor Rivaldo (R) & $\begin{array}{l}\text { Investigar duas relações métricas no triângulo re- } \\
\text { tângulo: em qualquer triângulo retângulo, a medi- } \\
\text { da da hipotenusa é igual à soma das medidas das } \\
\text { projeções dos catetos }(a=n+m) \text {, e o produto da } \\
\text { medida da hipotenusa pela medida da altura relati- } \\
\text { va a ela é igual ao produto das medidas dos catetos } \\
\text { (a.h=b.c). }\end{array}$ & $\begin{array}{l}\text { "Descobrindo relações mé- } \\
\text { tricas no triângulo retân- } \\
\text { gulo" }\end{array}$ \\
\hline $\begin{array}{l}\text { Professora Sofia } \\
\text { (S) }\end{array}$ & $\begin{array}{l}\text { Construir, reconhecer e definir ângulos consecu- } \\
\text { tivos e adjacentes; construir, reconhecer e definir } \\
\text { ângulos complementares e suplementares. }\end{array}$ & $\begin{array}{l}\text { "Construindo e reconhe- } \\
\text { cendo ângulos consecuti- } \\
\text { vos, adjacentes, comple- } \\
\text { mentares e suplementares } \\
\text { no Ensino Fundamental" }\end{array}$ \\
\hline $\begin{array}{l}\text { Professor Vanildo } \\
\text { (V) }\end{array}$ & $\begin{array}{l}\text { Identificar quadriláteros a partir de suas proprie- } \\
\text { dades. }\end{array}$ & $\begin{array}{l}\text { "Só o quadrado é quadrilá- } \\
\text { tero?" }\end{array}$ \\
\hline
\end{tabular}

A escolha dessas narrativas deve-se ao fato de que todas fazem parte do material produzido pela CoP-OEM e já publicado no ambiente virtual. A análise das narrativas foi realizada individualmente e, em seguida, organizada e cruzada em um quadro 2, no qual esboçamos o processo/produto que constitui a escrita de uma aula e o repertório comum da CoP-OEM. A partir desse quadro, geramos categorias gerais que descrevem conceitos e conexões que articulam as duas CoP.

14 http://www.educacaomatematica.ufba.br 
A seguir, apresentaremos o resultado do processo analítico e metodológico que reúne a ideia-chave do presente artigo.

\section{As narrativas como reificações entre comunidades de prática}

A produção de narrativas na CoP-OEM originou-se a partir do desenvolvimento dos MCE, ou seja, de uma produção mais ampla que caracteriza a prática social dessa comunidade. Em reuniões presenciais e virtuais, a comunidade negociou quais elementos deveriam compor o corpo de uma narrativa, de modo que todas as produções narrativas seguissem uma lógica comum. Tais elementos foram organizados em um documento denominado "Parâmetros para a produção de MCE". Nele também encontramos orientações para a produção dos demais itens que integram esse MCE. A seguir, apresentamos alguns desses elementos ${ }^{15}$ que compõem a produção de narrativa:

- Como a aula foi iniciada? (Quais as ações do professor e dos alunos nesse momento?).

- Como a leitura da tarefa foi feita? (Por quem foi feita? Pelo professor, partilhada com/pelos estudantes...?).

- Como a aula foi desenvolvida? (Como foi a interação estudante x estudante e estudante $\mathrm{x}$ professor?).

- Como os estudantes apresentaram suas conclusões/soluções? (Eles apresentaram de seus lugares, fizeram registros escritos, apresentaram no quadro ou com outros materiais, etc.?).

Do ponto de vista teórico, tais elementos podem ser compreendidos como um repertório compartilhado dessa comunidade, uma vez que incluem maneiras de fazer certas coisas, ações, palavras e rotinas que essa comunidade tem produzido e adotado no curso de sua existência. Esses elementos resumem "coisas" que devem conter na produção da narrativa, a saber: introdução da tarefa, leitura da tarefa, intervenção do professor durante sua realização; e conclusão da tarefa. Baseado nessas "coisas", construímos analiticamente o quadro 2, a fim de apresentar transversalmente formas de fazer e as experiências que foram projetadas por meio das narrativas.

15 Os elementos apresentados em tópicos não representam todos os que compõem a elaboração da narrativa. No documento norteador do grupo há outros elementos, como, por exemplo, mencionar: as características da escola e da turma; o modo como a tarefa foi entregue; o objetivo ou a proposta da tarefa; as dificuldades encontradas pelos estudantes e pelo professor. E apresentar trechos de falas dos alunos e imagens da sala de aula. A escolha de apenas alguns elementos ajudou a entender como a experiência foi projetada ou “congelada”, uma vez que esses dão mais detalhes quanto à forma de desenvolvimento da tarefa. 
Quadro 2: Reificações nas narrativas

\begin{tabular}{|c|c|c|c|c|c|c|}
\hline & Cecília (C) & Vanildo (V) & Giovanna $(\mathrm{G})$ & Mércia (M) & Rivaldo (R) & Sofia (S) \\
\hline $\begin{array}{c}\text { Introdução } \\
\text { (1) }\end{array}$ & $\begin{array}{l}\text { Familiariza os es- } \\
\text { tudantes com o } \\
\text { software Geogebra } \\
\text { antes da realização } \\
\text { da tarefa. Organiza } \\
\text { a turma em grupo e } \\
\text { faz a leitura da ta- } \\
\text { refa. }\end{array}$ & $\begin{array}{l}\text { Familiariza os es- } \\
\text { tudantes com os } \\
\text { instrumentos de } \\
\text { medida, com os } \\
\text { materiais mani- } \\
\text { puláveis e relem- } \\
\text { bra alguns concei- } \\
\text { tos da geometria: } \\
\text { paralelismo, reta, } \\
\text { ponto, etc. }\end{array}$ & $\begin{array}{l}\text { Organiza a turma } \\
\text { em grupos, expli- } \\
\text { ca o uso dos instru- } \\
\text { mentos de medida } \\
\text { na tarefa e entrega } \\
\text { os materiais aos es- } \\
\text { tudantes (uma fo- } \\
\text { lha com os triângu- } \\
\text { los e os instrumen- } \\
\text { tos de medida). }\end{array}$ & $\begin{array}{l}\text { Familiariza os es- } \\
\text { tudantes com o } \\
\text { software Geogebra } \\
\text { em momento an- } \\
\text { terior à aula. Or- } \\
\text { ganiza a turma em } \\
\text { duplas por causa } \\
\text { da quantidade de } \\
\text { computadores. }\end{array}$ & $\begin{array}{l}\text { Inicia retomando } \\
\text { os conceitos de tri- } \\
\text { ângulo retângulo, } \\
\text { catetos e hipotenu- } \\
\text { sa. Faz explorações } \\
\text { do kit com mate- } \\
\text { riais manipuláveis. }\end{array}$ & $\begin{array}{l}\text { Familiariza os es- } \\
\text { tudantes com o } \\
\text { software Geogebra, } \\
\text { antes do desenvol- } \\
\text { vimento da tarefa. } \\
\text { Organiza os estu- } \\
\text { dantes em duplas } \\
\text { devido à quantida- } \\
\text { de de computado- } \\
\text { res. }\end{array}$ \\
\hline $\begin{array}{c}\text { Leitura } \\
\text { (2) }\end{array}$ & $\begin{array}{l}\text { Faz a leitura de to- } \\
\text { da a tarefa junta- } \\
\text { mente com os es- } \\
\text { tudantes. }\end{array}$ & $\begin{array}{l}\text { Faz a leitura de to- } \\
\text { da a tarefa junta- } \\
\text { mente com os es- } \\
\text { tudantes. }\end{array}$ & $\begin{array}{l}\text { Não faz leitura da } \\
\text { tarefa com os estu- } \\
\text { dantes. }\end{array}$ & $\begin{array}{l}\text { O professor lê a ta- } \\
\text { refa passo a passo } \\
\text { em um esquema } \\
\text { leitura-resolução, } \\
\text { em que cada ques- } \\
\text { tão é respondida } \\
\text { após a sua leitura. }\end{array}$ & $\begin{array}{l}\text { Faz a leitura de to- } \\
\text { da a tarefa junta- } \\
\text { mente com os es- } \\
\text { tudantes. }\end{array}$ & $\begin{array}{l}\text { O professor lê a ta- } \\
\text { refa passo a passo } \\
\text { em um esquema } \\
\text { leitura-resolução, } \\
\text { em que cada ques- } \\
\text { tão é respondida } \\
\text { após a sua leitura. }\end{array}$ \\
\hline $\begin{array}{l}\text { Intervenção } \\
\text { (3) }\end{array}$ & $\begin{array}{l}\text { Relata interven- } \\
\text { ções nos grupos, } \\
\text { as quais levam os } \\
\text { alunos a refletir so- } \\
\text { bre suas soluções, } \\
\text { mas não dá a eles } \\
\text { uma resposta. Nas } \\
\text { intervenções para } \\
\text { toda a classe, ex- } \\
\text { plica/exemplifica } \\
\text { como fazer deter- } \\
\text { minado procedi- } \\
\text { mento. }\end{array}$ & $\begin{array}{l}\text { Revela ter feito in- } \\
\text { tervenção para a } \\
\text { classe inteira, rea- } \\
\text { lizada ao perceber } \\
\text { que os alunos esta- } \\
\text { vam usando o con- } \\
\text { ceito de ângulo re- } \\
\text { to para se referir ao } \\
\text { ângulo de } 180^{\circ} \text {. }\end{array}$ & $\begin{array}{l}\text { Reporta interven- } \\
\text { ções nos grupos, } \\
\text { ensinando a usar } \\
\text { os instrumentos de } \\
\text { medida e explican- } \\
\text { do o que era solici- } \\
\text { tado nas questões. }\end{array}$ & $\begin{array}{l}\text { Faz referência a in- } \\
\text { tervenções no qua- } \\
\text { dro para toda a } \\
\text { classe, a fim de ex- } \\
\text { plicar/exemplificar } \\
\text { como fazer um de- } \\
\text { terminado proce- } \\
\text { dimento. }\end{array}$ & $\begin{array}{l}\text { Revela ter feito in- } \\
\text { tervenções nos } \\
\text { grupos a fim de } \\
\text { compreender o } \\
\text { modo como os es- } \\
\text { tudantes resolve- } \\
\text { ram o problema e } \\
\text { faz intervenções } \\
\text { para toda a classe, } \\
\text { a fim de explicar o } \\
\text { significado do que } \\
\text { estava sendo pedi- } \\
\text { do na questão. }\end{array}$ & $\begin{array}{l}\text { Relata interven- } \\
\text { ções para toda } \\
\text { classe por meio de } \\
\text { questões gerais so- } \\
\text { bre a tarefa e, co- } \\
\text { mo os alunos apre- } \\
\text { sentam dificulda- } \\
\text { des, vai ao quadro } \\
\text { e explica por meio } \\
\text { de exemplos seme- } \\
\text { lhantes aos solici- } \\
\text { tados na tarefa. }\end{array}$ \\
\hline $\begin{array}{c}\text { Conclusão } \\
\text { (4) }\end{array}$ & $\begin{array}{l}\text { Revela ter procedi- } \\
\text { do a uma sistema- } \\
\text { tização dialogada, } \\
\text { fazendo questões } \\
\text { aos estudantes pa- } \\
\text { ra além daquelas } \\
\text { apresentadas na } \\
\text { tarefa, a fim de que } \\
\text { os estudantes en- } \\
\text { contrem uma for- } \\
\text { ma geral para so- } \\
\text { ma das medidas } \\
\text { dos ângulos inter- } \\
\text { nos de um polígo- } \\
\text { no. O professor } \\
\text { não relata sociali- } \\
\text { zação dos resulta- } \\
\text { dos, mas reporta } \\
\text { uma sistematiza- } \\
\text { ção dos conteúdos } \\
\text { e dos procedimen- } \\
\text { tos. }\end{array}$ & $\begin{array}{l}\text { Relata uma siste- } \\
\text { matização dialoga- } \\
\text { da a partir das res- } \\
\text { postas de dois gru- } \\
\text { pos em um slide. } \\
\text { Embora não repor- } \\
\text { te socialização das } \\
\text { respostas de to- } \\
\text { dos os estudantes, } \\
\text { o professor relata } \\
\text { sistematização dos } \\
\text { conceitos e apre- } \\
\text { senta nomencla- } \\
\text { turas. }\end{array}$ & 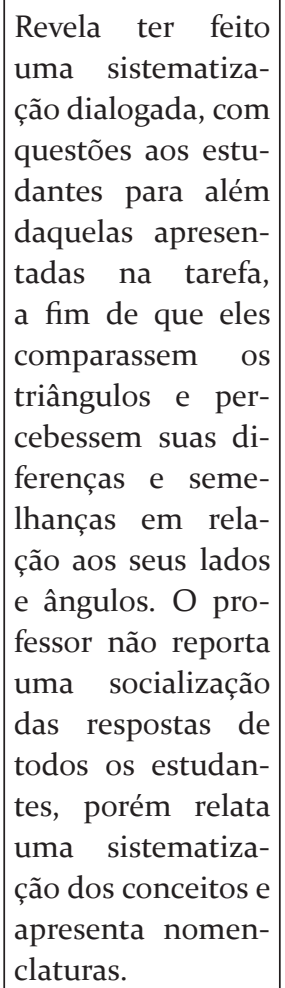 & $\begin{array}{l}\text { Relata uma siste- } \\
\text { matização a par- } \\
\text { tir das questões da } \\
\text { própria tarefa e faz } \\
\text { uma revisão das } \\
\text { classificações de } \\
\text { triângulos, ângu- } \\
\text { los, etc. O profes- } \\
\text { sor não socializa as } \\
\text { respostas de todos } \\
\text { os estudantes, po- } \\
\text { rém revela ter fei- } \\
\text { to a sistematização } \\
\text { dos conceitos e re- } \\
\text { lembra nomencla- } \\
\text { turas. }\end{array}$ & $\begin{array}{l}\text { Reporta que uma } \\
\text { aluna socializa os } \\
\text { procedimentos pa- } \\
\text { ra encontrar as so- } \\
\text { luções. O professor } \\
\text { não relata a socia- } \\
\text { lização de outros } \\
\text { membros nem a } \\
\text { sistematização. }\end{array}$ & $\begin{array}{l}\text { Relata uma siste- } \\
\text { matização feita a } \\
\text { partir de exemplos } \\
\text { similares aos soli- } \\
\text { citados nas ques- } \\
\text { tões da tarefa e } \\
\text { também uma siste- } \\
\text { matização dos con- } \\
\text { ceitos. E apresenta } \\
\text { nomenclaturas. }\end{array}$ \\
\hline
\end{tabular}


Na linha 1, identificamos relatos quanto às formas de introdução da tarefa desenvolvida na comunidade de sala de aula. Podemos identificar que, em C1, M1 e S1, houve uma familiarização dos estudantes com o software Geogebra antes da realização da tarefa. O uso do software parece reforçar uma ação comum entre os professores, a fim de evitar dificuldades no manuseio dessa tecnologia digital. Já em V1, G1 e R1, houve uma familiarização dos estudantes com os instrumentos de medidas e os materiais manipuláveis utilizados na tarefa. Assim como no caso do software, os professores sentiram a necessidade de familiarizar os estudantes com os materiais manipuláveis antes de desenvolver a tarefa.

Na introdução, também identificamos que, em C1, M1 e S1, houve organização dos estudantes em duplas ou trios. Já em V1, G1 e R1, eles foram organizados em grupos maiores. Em todos os casos, os estudantes desenvolveram as tarefas partilhando ideias uns com os outros. Nas narrativas, não há uma justificativa quanto a essa organização, embora, em M1 e S1, haja indícios de que ela decorreu do contexto escolar, suscitando que a tarefa fosse desenvolvida individualmente.

Na linha 2, extraímos relatos das formas de leitura da tarefa. Em C2, V2 e R2, houve leitura de toda a tarefa juntamente com os estudantes. Em G2, isso não aconteceu. Já em M2 e S2, a leitura da tarefa foi realizada passo a passo, explicando questão por questão, de modo a possibilitar que todos os estudantes desenvolvessem a tarefa ao mesmo tempo. No relato, não encontramos justificativas em relação a essas maneiras de fazer a leitura da tarefa, mas identificamos certos padrões entre elas.

Já na linha 3, apontamos relatos referentes às formas de intervenção do professor durante a tarefa, as quais se caracterizaram pela maneira como acontece a interação entre professor e estudantes. Em C3, M3 e S3, houve relatos de intervenções do professor de maneira coletiva para toda a classe, com a utilização do recurso da lousa, a fim de exemplificar/explicar como fazer um determinado procedimento solicitado na tarefa. Diferentemente, em R3 e G3 houve intervenções em cada grupo, quando necessário, com intuito de explicar ou reinterpretar o que estava sendo solicitado na questão. Nesse último caso, os professores perceberam dificuldades de compreensão da questão ou de natureza matemática.

Por fim, na linha 4 , sintetizamos relatos relativos às formas de conclusão da tarefa. Em C4, G4 e V4, houve sistematização da tarefa, pelo professor, de forma dialogada, a fim de formalizar o conteúdo e introduzir outros conceitos e/ou conteúdos, bem como outras nomenclaturas que podem ser desencadeadas a partir da resolução da tarefa. Isso também acontece em M4 e S4; entretanto, nessas duas últimas, de forma diversa dos demais relatos, houve sistematizações com a finalidade de fixar os conteúdos propostos por meio da tarefa. Em R4, encerrou-se a tarefa após um grupo ter exposto sua solução no quadro para os demais. Nesse último caso, não 
há um relato quanto à sistematização realizada pelo professor, mas socialização de um grupo de estudantes.

Apesar de identificarmos semelhanças ou diferenças nas formas de relatar a experiência, elas possuem vida própria e apresentam, explícita ou implicitamente, relações pedagógicas diferentes entre professores e estudantes. Dessa maneira, as narrativas são documentos que relatam e projetam a realidade, ou seja, congelam maneiras de escrever acerca da experiência. Baseados na teoria de Wenger (1998), podemos interpretar as narrativas como reificações que fazem referência, ao mesmo tempo, ao produto (documento escrito pela comunidade OEM) e ao processo (experiência de participação na comunidade de sala de aula), que se implicam mutualmente.

A tarefa elaborada na CoP-OEM e desenvolvida na comunidade de sala de aula representa um fio condutor entre essas comunidades e assume papéis distintos quando ativa dentro delas. Tanto a tarefa quanto a narrativa são reificações da comunidade OEM, uma vez que foram ali elaboradas, mas subsidiadas por outra. Particularmente, à luz da teoria, a tarefa pode ser vista - reiteramos - como um objeto de fronteira que conecta as duas comunidades de prática; e o professor, um broker que realiza essa conexão. Assim, as narrativas são reificações ocasionadas por um objeto de fronteira e pela ação de um broker.

Por outro lado, o quadro sintetiza determinados repertórios compartilhados na comunidade OEM, a fim de elaborar determinadas maneiras na escrita da narrativa, tais como os elementos (1), (2), (3) e (4). De acordo com Wenger (2001):

O repertório de uma comunidade de prática inclui: símbolos, rotinas, palavras, ações, conceitos, artefatos, maneiras de fazer certas coisas, gestos, os quais foram produzidos ou incorporados pela comunidade ao longo de sua trajetória. Os elementos do repertório podem ser heterogêneos e combinam elementos de reificação e de participação. (p. 110)

Assim, os repertórios combinam elementos da participação de brokers e estudantes na CoP-Sala de aula (o cruzamento de [C], [V], [G], [M], [R], [S] com [1], [2], [3], [4]) e elementos da reificação, os quais foram abreviados de "coisas", que devem incorporar as narrativas, bem como esse mesmo cruzamento, que propicia diferentes formas.

Portanto, tais “coisas”, elementos e cruzamentos, são reificações das narrativas, o que, por consequência, significa que são reificações das reificações. Ou seja, as narrativas podem ser compreendidas teoricamente como (re)reificações de uma comunidade interconectada com outra comunidade (ou outras comunidades) a partir do objeto de fronteira. 
No sentido apresentado, o conceito de (re)reificações está relacionado às conexões entre comunidades de prática e, por sua vez, não representa o mero resultado da participação em uma comunidade, mas envolve tanto a participação de sujeitos em duas ou mais delas quanto a negociação de significados entre as comunidades envolvidas.

\section{Considerações finais}

As narrativas podem ser vistas como resultado de um processo de participação e negociação de significados, interconectadas por uma ou mais de uma CoP. Por outro lado, também podem ser consideradas como objetos capazes de congelar uma determinada prática, a fim de que essa seja revisitada, refletida, reinterpretada tanto pelo próprio professor, que desenvolveu a tarefa na sala de aula, como por seus pares. Isso se deve ao fato de que a reificação "não apenas dá forma ou expressão a significados existentes, mas cria condições para novos significados" (Wenger, 2001, p. 84). Portanto, a narrativa é um exemplo típico de uma reificação que representa tanto o processo de participação quanto o produto final.

De acordo com Wenger (2001), a reificação não pressupõe uma correspondência intrínseca entre um fenômeno e uma interpretação, mas, ao contrário, esse conceito sugere que as formas podem possuir "vida própria" além de seu contexto de origem, adquirindo um grau de autonomia em relação à ocasião e aos propósitos de sua produção. Desse modo, as narrativas têm "vida própria” quando outros professores a utilizam para compreender formas de fazer ou conduzir uma tarefa, a fim de transformá-la na prática pedagógica. Assim, seu significado sempre se amplia, proporcionando novos sentidos a essa reificação.

Em contrapartida, o próprio Wenger (2001) destaca que esse significado também pode se perder ou tornar-se objeto de alienação, o que ocorre quando os professores utilizam e compreendem as narrativas como um congelamento estático e fixo, gerando um modelo ou roteiro a seguir e a tendência a fazer conforme foi visualizado. Trata-se de uma consequência inevitável, quando se apresentam formas de desenvolver uma tarefa. Embora o teórico reconheça tal consequência, ele aponta que a reificação, como componente do significado, sempre é algo incompleto, contínuo, potencialmente enriquecedor. Entretanto, pode também ser algo enganoso ou perigoso. Dessa maneira, a reificação envolve um duplo significado.

Assim como na CoP-GdS, a CoP-OEM também reifica ideias, conceitos, saberes, materiais, maneiras de fazer e escrever, próprios, dentro de uma reificação mais ampla, que corresponde às narrativas. A análise anterior suscita que há um conjunto de reificações, uma vez que depende de outras reificações, bem como a tarefa, que, por exemplo, corresponde também a um objeto de fronteira entre duas 
CoP. A participação do professor nessas duas comunidades proporciona conexões que articulam as reificações e os objetos de fronteiras, gerando novas reificações. Com isso, o professor assume o papel de broker, ao estabelecer essas conexões.

Portanto, concluímos que as reificações (narrativas) podem ser utilizadas em espaços de formação inicial ou continuada, para que outros brokers possam produzir diferentes interpretações e novos significados, ao utilizar e transformar, também, o objeto de fronteira (tarefa). Essa perspectiva considera as narrativas como reificações enriquecedoras, mas podem se tornar empobrecedoras, a depender do uso que se faz dela. Os resultados deste artigo não dão conta das consequências, mas podem expor diferentes formas de reificar determinadas reificações e objetos de fronteira. Diante disso, reconhecemos que outras investigações futuras podem ser desenvolvidas para analisar as consequências do uso dessas (re)reificações.

\section{Referências}

Alves-Mazzotti, A. J. (2002). O planejamento de pesquisas qualitativas. In A. J. Alves-Mazzotti, \& F. Gewandsznajder, $O$ método das ciências naturais e sociais: pesquisa quantitativa e qualitativa (pp. 129-178) São Paulo: Pioneira.

Beline, W. (2012). Formação de professores de matemática em comunidades de prática: um estudo sobre identidades. Tese de Doutorado em Ensino de Ciências e Educação Matemática, Universidade Estadual de Londrina, Londrina.

Cristovão, E. M., \& Castro, J. F. (2013). Possibilidades e limites da postura colaborativa e investigativa do professor como tática de enfrentamento da complexidade da docência. Espaço Pedagógico, 20(1), 158-174.

Cyrino, M. C. C. T. (2013). Formação de professores que ensinam matemática em comunidades de prática. 7 Anais do Congresso Iberoamericano de Educação Matemática. Montevideo: CBEM.

Fiorentini, D. (2009). Quando acadêmicos da universidade e professores da escola básica constituem uma comunidade de prática reflexiva e investigativa. In D. Fiorentini, R. C. Grando, \& R. G. Miskulin (Orgs.), Práticas de formação e de pesquisa de professores que ensinam matemática (pp. 233-255). Campinas: Mercado de Letras.

Johnson, B., \& Christensen, L. (2012). Educational research: quantitative, qualitative, and mixed approaches. Thousand Oaks: Sage.

Lave, J., \& Wenger, E. (1991). Situated learning: Legitimate peripheral participation. Cambridge: Cambridge University Press.

Lucena, T. V. (2014). Aprendizagens de professores de matemática a partir da participação em um grupo colaborativo. Dissertação de Mestrado em Ensino,

Filosofia e Histórias das Ciências, Universidade Federal da Bahia, Salvador e Universidade Estadual de Feira de Santana, Feira de Santana. 
Maciel, D. M., Braga, K. R., \& Olanda, M. R. S. (2008). Formação colaborativa de docentes de matemática: um diálogo entre a educação básica e a universidade. Anais do Simpósio Internacional de Pesquisa em Educação Matemática. Recife.

Marquesin, D. F. B, \& Passos, L. F. (2009). Narrativa como objeto de estudo: aportes teóricos. Múltiplas Leituras, 2( 2), 219-237.

Nacarato, A. M, Passos, C. L. B., \& Silva, H. (2014). Narrativas na pesquisa em Educação Matemática: caleidoscópio teórico e metodológico. Bolema - Boletim de Educação Matemática, 28(49), 701-716.

Nagy, M, C. (2013). Trajetórias de aprendizagem de professoras que ensinam matemática em uma comunidade de prática. Tese de Doutorado em Ensino de Ciências e Educação Matemática, Universidade Estadual de Londrina, Londrina.

Passos, C., \& Galvão, C. (2011). Narrativas de formação: investigações matemáticas na formação e na atuação de professores. Interacções, 18(7), 76-103.

Pereira, J. S. (2013). Materiais manipuláveis e a participação de estudantes: engajamento mútuo e repertório compartilhado nas aulas de matemática.

Dissertação de Mestrado em Ensino, Filosofia e Histórias das Ciências. Salvador: Universidade Federal da Bahia e Universidade Estadual de Feira de Santana, Feira de Santana.

Pereira, M. N. M. (2013). Geometria, situações com referência na realidade e a participação de estudantes em aulas de matemática. Dissertação de Mestrado em Ensino, Filosofia e Histórias das Ciências. Universidade Federal da Bahia, Salvador e Universidade Estadual de Feira de Santana, Feira de Santana.

Rocha, M. R., \& Cyrino, M. C. C. T. (2012). Um estudo sobre empreendimentos de uma comunidade de prática de professores de matemática na busca de aprender e ensinar frações. 16 Anais do Encontro Brasileiro de Estudantes de Pós-Graduação em Educação Matemática, Recife.

Schneider, R. M., \& Krajcik, J. (2002). Supporting science teacher learning: The role of educative curriculum materials. Journal of Science Teacher Education, 13(3), 221-245.

Souza, J. V. B. (2011). Os materiais manipuláveis e a participação dos alunos na aula de matemática. Dissertação de Mestrado em Ensino, Filosofia e Histórias das Ciências, Universidade Federal da Bahia, Salvador e Universidade Estadual de Feira de Santana, Feira de Santana.

Wenger, E. Communities of practice: Learning, meaning and identity. New York: Cambridge University Press, 1998.

Wenger, E. Comunidades de prática: Aprendizaje, significado e identidad. Barcelona: Paiadós, 2001.

Submetido em: 20/01/2016

Aceito em: 05/03/2016 
